\title{
In situ measures of spawning synchrony and fertilization success in an intertidal, free-spawning invertebrate
}

\author{
Dustin John Marshall* \\ Department of Zoology, University of Melbourne, Melbourne, Victoria 3010, Australia
}

\begin{abstract}
The rocky intertidal zone has the potential to be one of the harshest environments for free-spawning organisms, but empirical data on fertilization success are scarce. Here, I report on an intertidal, solitary ascidian, Pyura stolonifera, which was observed to spawn at low tide. At a scale likely to be most important to gametes (metres, duration of tide), approximately $30 \%$ of individuals in the population were spawning synchronously. Spawned gametes remained in a viscous matrix and this appeared to minimise their dilution. Fertilization success varied greatly among individuals ( 0 to $92 \%$ ) and was related to the distance to the nearest neighbouring spawner. Occasional wave wash facilitated the movement of sperm between spawners. Fertilization success in some individuals was limited by the scarcity of sperm whilst the experimental addition of sperm did not increase success in others.
\end{abstract}

KEY WORDS: Fertilization kinetics $\cdot$ Broadcast spawner $\cdot$ Ascidian $\cdot$ Reproductive success Resale or republication not permitted without written consent of the publisher

\section{INTRODUCTION}

The problems associated with reproducing by free spawning and their ecological implications are well recognised (Yund 2000). Intuitively, if fertilization success is very low, then population growth could be limited by the rate at which eggs are fertilized (Levitan \& Petersen 1995). Also, population density may positively affect reproductive success by increasing fertilization rates (Levitan 1995). Whilst the broad-scale consequences of free-spawning are known, data on the fertilization success of free-spawners exist for very few species (Yund 2000). We now understand how varying concentrations of sperm affect fertilization success for a range of organisms and a number of models have been produced to describe this relationship (e.g. Styan \& Butler 2000, Powell et al. 2001). Our ability, however, to make predictions about likely sperm concentrations and thus, fertilization rates in the field, remains highly limited (Yund 2000).

*E-mail: d.marshall@zoology.unimelb.edu.au
If we hope to predict likely fertilization rates from population densities in the field, then estimates of spawning synchrony are required. A number of studies have examined how fertilization success is affected by increases in effective spawner density (Levitan 1995). However, in order to link effective spawner density to population density, estimates of the synchrony with which individuals in the population spawn are needed.

One of the most interesting marine habitats for the study of fertilization is the rocky intertidal zone. Shearstresses on gametes and high rates of turbulent dilution are predicted to strongly negatively affect fertilization success (Denny \& Shibata 1989). However, some data suggest that reproduction by free-spawning algae in this environment can be very successful, particularly if spawning occurs at low tide when water turbulence is low. This results in high fertilization rates and, in some cases, polyspermy (Brawley 1992, Serrao et al. 1996, Speransky et al. 2000). In contrast, our knowledge of the spawning behaviours of rocky intertidal invertebrates and the success of those behaviours is non-existent. 
I observed the natural spawning of the intertidal, solitary ascidian Pyura stolonifera in the field. I addressed a number of questions in this study, specifically: (1) What was the fertilization success of individuals within a naturally spawning population and what factors affected fertilization success? (2) Was fertilization success limited by the scarcity of sperm? (3) How synchronously did individuals within the population spawn? (4) Were any spawning behaviours apparent that might increase fertilization success? In addition, because individual $P$. stolonifera are hermaphrodites that release eggs and sperm simultaneously, I also determined their ability to self-fertilize.

\section{MATERIALS AND METHODS}

Study site. The study site was located at Thirteenth Beach, Barwon Heads, Victoria, Australia. Spawning of Pyura stolonifera was observed at 3 reefs within this site, hereafter named Reef 1, Reef 2 and Reef 3 . Reef 1 was separated from Reef 2 by a surge channel approximately $3 \mathrm{~m}$ wide. Reef 3 was separated from Reef 2 by a $1 \mathrm{~m}$ wide surge channel and approximately $13 \mathrm{~m}$ of rock that was free of $P$. stolonifera. Each reef was a large flat platform. During low tide, waves typically break immediately in front of the platforms and swash runs over the length of platform and throughout the distribution of $P$. stolonifera. All observations were made in January and February 2001.

Gonad indices. From Reef 1, I collected 12 haphazardly chosen Pyura stolonifera on January 30 (1 d prior to observed spawning period) and $12 \mathrm{P}$. stolonifera $1 \mathrm{~d}$ after the observed spawning period (February 2). I removed, by dissection, the gonad and visceral mass of each $P$. stolonifera, blotted each on absorbent paper and recorded the wet weights of the viscera and gonad to the nearest $0.1 \mathrm{~g}$. The ratio of gonad to visceral mass was then calculated. To determine whether all the individuals were spent, I collected, dissected and examined a further haphazardly chosen 50 individuals from Reefs 2 and 3, $1 \mathrm{~d}$ after the spawning period.

Spawning behaviour. There were 3 observed, sequential spawning events, each coinciding approximately with the predicted low tide. For all 3 low tides, just prior to immersion by the incoming tide, quadrats (circular, $1 \mathrm{~m}$ diameter) were thrown haphazardly until approximately 60 Pyura stolonifera were sampled. Because spawned gametes remained in a viscous matrix on top of the individual spawners throughout the low tide, I did not have to observe spawning in order to class animals as 'spawned'. Animals were classed as 'not spawned' if no evidence of spawning was observed.
For the second low tide, I assessed the proportion of spawning individuals at any one time. In a single minute, I counted how many animals were actively spawning and how many were not. Twenty-six observers were distributed haphazardly and each counted animals only in their immediate viewing area (sampling was at night, viewing area was about $2 \mathrm{~m}$ in diameter). I repeated sampling in this manner every half hour for Reef 1 and Reef 2 for approximately $2 \mathrm{~h}$.

On the third low tide, 12 individuals that had not yet spawned were observed from the moment they started spawning. I measured the time course of spawning and maintained continual observation of them for $20 \mathrm{~min}$. These individuals were marked with flagging tape and 6 were dissected immediately after the observation period; later, their gonads and viscera were weighed. The remaining 6 marked individuals were removed from the rock platform the following day and taken back to the laboratory in individual, sealed plastic bags with some seawater. These individuals were then examined using a dissecting microscope for eggs, sperm and zygotes on the surface of the tunic. The water in which each was transported was also examined for gametes and zygotes.

Self-fertilization. I found that almost all spawning individuals in the field simultaneously released both sperm and eggs. Therefore I was interested in whether Pyura stolonifera were capable of self-fertilization. I collected ripe individuals and conducted fertilization trials using strip-spawned gametes according to the method outlined in Marshall et al. (2000). Eggs from 4 individuals were each divided into 2 groups and

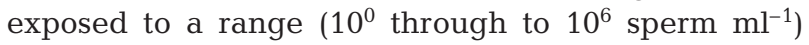
of self or non-self sperm concentrations. I then determined the maximum fertilization success of eggs exposed to self and non-self sperm and compared these values using a paired $t$-test.

Fertilization success and distance. I was interested in the relationship between fertilization success of individual Pyura stolonifera distance to the nearest other spawning individual. I could assess individual fertilization success because spawned eggs remained on the surface of the spawners. For each of the 3 tides during which spawning occurred, I sampled spawned eggs from haphazardly selected individuals by drawing $2 \mathrm{ml}$ of gamete matrix into a $10 \mathrm{ml}$ syringe. This syringe was immediately filled with a further $8 \mathrm{ml}$ of seawater that was collected from a beach $\sim 1 \mathrm{~km}$ from the nearest $P$. stolonifera population. This solution was then immediately rinsed with $500 \mathrm{ml}$ of seawater using a $100 \mu \mathrm{m}$ plankton mesh to retain the eggs. The eggs were then left to incubate in $20 \mathrm{ml}$ of fresh seawater in polyethylene vials. Two hours after collection, I fixed the sample using a few drops of formalin. From each 
sample, I examined 100 randomly selected eggs and classed them as either fertilized or not fertilized. Eggs that showed normal cleavage patterns were considered fertilized. In ascidians generally, and particularly $P$. stolonifera, polyspermic eggs divide rarely and therefore I could not distinguish between polyspermic and unfertilized eggs (Lambert \& Lambert 1981, Marshall et al. 2000).

At the time of collection of eggs, I measured the distance to the nearest individual spawner. Spawners were defined as those individuals with gametes visible around the exhalent siphon. I also noted the direction in relation to the shoreline of the nearest spawning individual. I classed nearest spawning individuals as perpendicular to the shoreline or parallel to the shoreline, because these directions correspond to upstream and cross-stream wave currents respectively. If the nearest spawner was not obviously perpendicular or parallel to the sampled individual in relation to the shoreline, no direction was recorded. I collected 48 samples and was able to determine the direction of the nearest spawner for 35 of them.

I analysed the effects of distance of the nearest spawner and direction in relation to the shoreline to the nearest spawner using ANCOVA, pooling across the 3 tides.

Determinants of limited fertilization success: I hypothesised that the fertilization success of spawners that were relatively isolated from other spawners was likely to be low due to the scarcity of sperm. To test this, I exposed eggs from isolated individuals with low fertilization success to additional sperm. I collected eggs from isolated individuals (those that were more than $2 \mathrm{~m}$ from the nearest spawner) and rinsed them as outlined above. This $20 \mathrm{ml}$ sample was then divided in half and one part was exposed to $10 \mathrm{ml}$ of fresh seawater, whilst the other was exposed to $10 \mathrm{ml}$ of freshly strip-spawned sperm at a concentration of $10^{3}$ sperm $\mathrm{ml}^{-1}$ (see Marshall et al. 2000 for method). Two h after collection, I fixed the sample with a few drops of formalin. Fertilization success was assessed as outlined above.

I hypothesised that some individuals had limited fertilization because of polyspermy. To test this, I exposed eggs from individuals that were adjacent to other spawning individuals to additional sperm. Collection, exposure of eggs to additional sperm and assessment of fertilization success were identical to the method for testing sperm limitation as outlined above. I repeated the sperm limitation and the polyspermy limitation trials using 4 different individuals, each time with a different sperm source. I compared fertilization success of eggs that either had or had not been exposed to additional sperm using paired $t$-tests.

\section{RESULTS}

\section{Gonad indices}

The gonad index of Pyura stolonifera collected from Reef 1 fell sharply after the observed spawning event for individuals from a range of sizes $(\mu \mathrm{m} \pm \mathrm{SE}$ before $=$ $0.893 \pm 0.015$, after $=0.269 \pm 0.012$ ). A further 50 individuals from Reef 2 and Reef 3 were dissected $1 \mathrm{~d}$ after the spawning event and all were completely spent.

\section{Spawning and synchrony behaviour}

Spawning of Pyura stolonifera was observed on 3 successive low tides beginning on the morning tide of January 31 . The 3 low tides occurred at 11:10 h $(0.31 \mathrm{~m}$ above MLLW; tidal range $\sim 1.5 \mathrm{~m}), 23: 09 \mathrm{~h}(0.3 \mathrm{~m}$ above MLLW) on January 31 and 11:42 h on February 1 ( $0.26 \mathrm{~m}$ above MLLW). The moon was in its first quarter. At each low tide, I observed spawning begin about 15 min after the majority of $P$. stolonifera were exposed and 'virgin' spawning individuals continued to initialise spawning throughout the low tide. No spawning behaviour was observed once individuals were immersed totally by the incoming tide although visibility was limited.

Individuals spawned by shedding gametes through their exhalent siphons. Of the 12 spawners that were extensively observed, all were seen to eject sperm and eggs simultaneously. This spawning lasted from 6 to $32 \mathrm{~s}$. However, during the course of the spawning period, 1 individual was observed to spawn eggs only and another was observed to spawn only sperm. After initial spawning, 8 out of the 12 individuals were seen to shed gametes a second time. This second spawning appeared to be far less forceful and fewer gametes were shed. I dissected 6 individuals 20 min after first being observed to spawn. In each, the gonads appeared completely spent and the branchial basket contained only a few eggs (approx. 30 eggs ind. ${ }^{-1}$ ) that, later, did not show any signs of fertilization. The gonad index of these 6 individuals did not significantly differ from the gonad index of the remaining 6 individuals when they were dissected the following day ( $t$-test, $t=1.24, \mathrm{df}=10, \mathrm{p}=0.244$ ).

The majority of the shed gametes remained intermingled in a viscous matrix on top of spawning individuals and gametes were present throughout the whole low tide. Sperm remained highly concentrated on the top surface of the tunic throughout the low tide $\left(\sim 10^{6}\right.$ sperm $\mathrm{ml}^{-1}$, data not shown). It is possible that the shed gametes remained on the surface throughout the subsequent high tide, but when the remaining 6 marked spawners were brought back to the laboratory 
on the next low tide, no sperm or eggs could be retrieved from, or observed on, the tunic. The surface of the Pyura stolonifera tunic is very complex and it is possible that some eggs may have remained in small pits and crevices that were impossible to examine. Nevertheless, the vast majority of eggs and sperm had disappeared during the high tide.

Spawning was patchily distributed at a range of scales. Of the 240 sea-squirts that were counted over the 3 low tides, $75(\sim 31 \%)$ were either observed to spawn or showed signs of recent spawning. On the first low tide, out of the 52 sea-squirts counted on Reef 1,16 $(\sim 31 \%)$ were either observed to spawn or showed signs of recent spawning. Despite being separated from Reef 1 by only a narrow surge channel, no spawning or sign of recent spawning was observed on the adjacent Reefs 2 or 3.

On the second low tide that spawning was observed, spawning occurred at Reefs 1 and 2 but not Reef 3 . The proportion of spawning individuals was greatest in the first 2 sampling periods during this low tide on Reef 2 but remained relatively low throughout the low tide on Reef 1 (Fig. 1). Of the 61 sea-squirts counted, 34 $(\sim 55 \%)$ were either observed to spawn or showed signs of recent spawning on Reef 2 . Of the 52 seasquirts counted on Reef 1 , only $3(\sim 5 \%)$ were either observed to spawn or showed signs of recent spawning during that low tide.

On the final tide that spawning was observed, spawning was only observed on Reef 3 . Of the 76 seasquirts counted, $22(\sim 29 \%)$ were observed to have either spawned or to have shown signs of spawning recently.

\section{Self-fertilization}

Strip-spawned eggs were fertilized at much higher rates using exogenous sperm than using self sperm. The maximum rate of fertilization using exogenous sperm was significantly higher than the maximum rate of fertilization using self sperm (mean difference: $45 \%$,

Table 1. ANCOVA comparing fertilization success (\% arcsine transformed) of individual Pyura stolonifera at different distances (metres, square root transformed) and position from the nearest neighbouring spawner. Model is reduced after testing for homogeneity of slopes

\begin{tabular}{|lccccr|}
\hline Source & SS & df & MS & $F$ & $p$ \\
\hline Distance & 1.457 & 1 & 1.457 & 29.4 & $<0.001$ \\
Position & 0.509 & 1 & 0.509 & 10.270 & 0.003 \\
Error & 1.585 & 32 & 0.050 & & \\
\hline
\end{tabular}

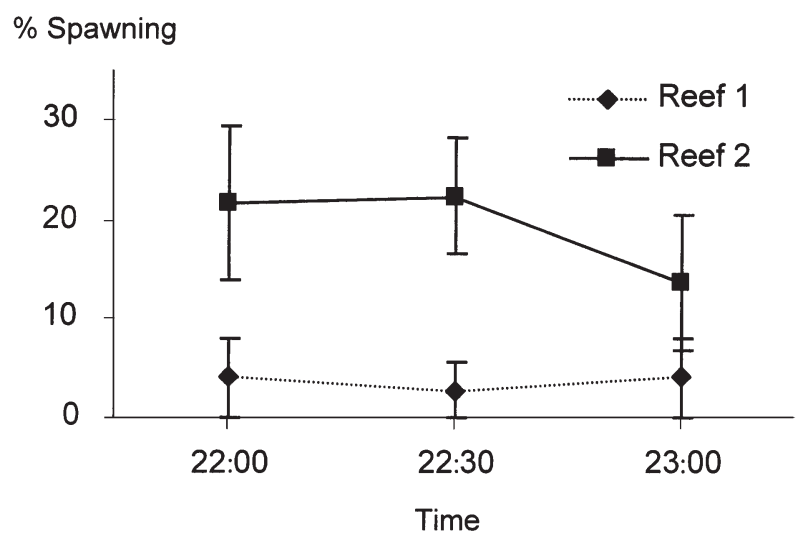

Fig. 1. Pyura stolonifera. Synchrony of spawning at 2 reefs in Barwon Heads, Australia, during 1 low tide on 31/01/01. Graph shows mean $( \pm \mathrm{SE})$ percentage of individuals observed spawning. No spawning was observed at Reef 3 during this low tide

SD $24 \%$; paired $t$-test, $t=3.75, \mathrm{df}=3, \mathrm{p}=0.033$ ). Ideally, I would have compared the sperm concentration at which fertilization success was maximised (i.e. $F_{\max }$, see Marshall et al. 2000). However, successful fertilization using self sperm was only observed in 2 samples of eggs, each from a different mother. Therefore, it was impossible to calculate $F_{\max }$ for the self-fertilization trials. The greatest fertilization success observed using self sperm was $15 \%$ and at every sperm concentration, fertilization success was higher using non-self sperm than using self sperm. In contrast, non-self sperm typically produced fertilization rates of $\sim 50 \%$ ( $\mathrm{SE}=9 \%$ )

\section{Fertilization success and distance}

Field fertilization success of individual Pyura stolonifera ranged between 0 and $92 \%$; mean fertilization rate over the 3 low tides was $45.2 \%(\mathrm{SD}=24.8)$. Fertilization success depended on the distance of the nearest neighbouring spawner and the position of that spawner relative to wave movement (Table 1, Fig. 2). Individual fertilization success was greatest in individuals directly adjacent to other spawners perpendicular to the shoreline. Individual fertilization success decreased rapidly with increasing distance between spawners and was very low when spawners were separated by more than $2 \mathrm{~m}$ (Fig. 2).

\section{Test of sperm limitation/polyspermy limitation}

The addition of sperm greatly increased the fertilization rate of eggs from isolated (putatively sperm- 


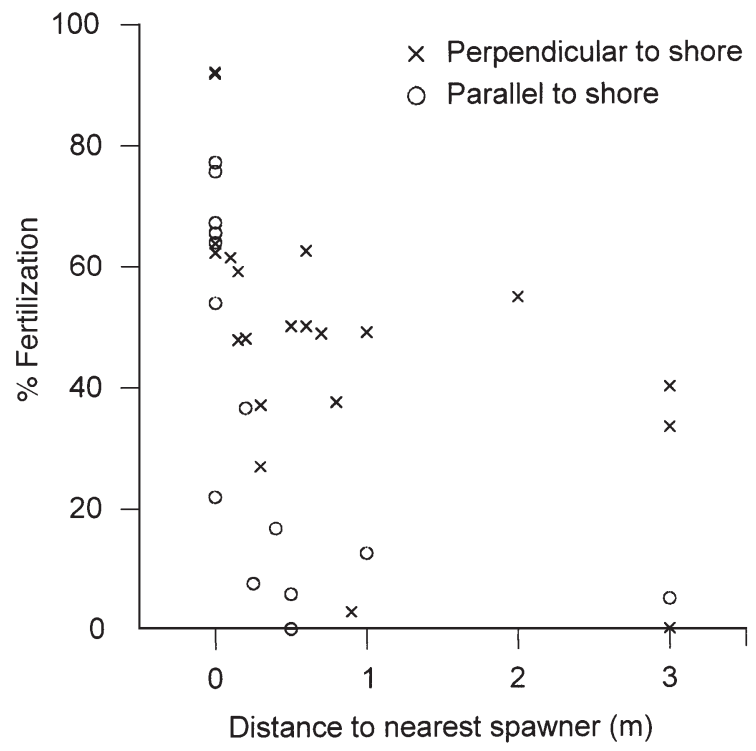

Fig. 2. Effect of distance and position of the nearest neighbouring spawner on the fertilization success of individual Pyura stolonifera at Barwon Heads, Australia. Results shown for all 3 low tides where spawning was observed

limited) individuals (mean difference in fertilization success: $37.4 \%, \mathrm{SD} 19.4$; paired $t$-test, $t=5.54$, df $=5$, $\mathrm{p}=0.002$ ). The addition of sperm had no significant effect on the fertilization rate of eggs from individuals in close proximity (mean difference in fertilization: $-4.2 \%$, SD 10.4; paired $t$-test, $t=1.55, \mathrm{df}=5, \mathrm{p}=0.18$ ).

\section{DISCUSSION}

In the absence of observations of spawning events, gonad indices are often used to infer the timing and synchrony of spawning events (e.g. Lasiak 1990). Often these indices show a uniform and dramatic drop after a putative spawning event (e.g. Parsons et al. 1992). From these data and observations of mass spawnings, it is sometimes assumed that spawning synchrony is extremely high (e.g. Clareboudt 1999). Here, I observed a uniform drop in the gonad index of Pyura stolonifera immediately following an observed spawning event. However, spawning was highly asynchronous among reefs. Furthermore, at the scale that is most likely to affect fertilization success (metres) and over a timescale more relevant to the spawned gametes (the duration of low tide), spawning synchrony was surprisingly low. As a result, the density of spawning individuals was far less than the actual population density. Caution should be taken when inferring spawning synchrony (and thus likely fertilization rates) from gonad indices in the absence of direct observations of spawning events. Furthermore, it may not be appropriate to assume that population density is equivalent to spawner density.

Pyura stolonifera were observed to release sperm and eggs simultaneously throughout the spawning event, suggesting that self-fertilization is possible. However, in the laboratory, fertilization rates using homologous sperm were never more than $15 \%$. Furthermore, the use of strip-spawned gametes has been suggested to overestimate self-fertilization levels (Fuke \& Numakunai 1996). It appears, therefore, that very little self-fertilization takes place during natural spawning in this species, especially given the lowfertilization success of isolated individuals.

Given the relatively low level of spawning synchrony within each reef and the minimal level of selffertilization in Pyura stolonifera, it is reasonable to expect field fertilization rates to be very low. However, fertilization rates were surprisingly high. Several factors probably contributed to the observed fertilization rates, specifically the timing of gamete release and the highly limited dispersal of gametes. By spawning at low tide, the exposure of gametes to the turbulent waters typical of the rocky intertidal was minimal. As in some species of intertidal algae, this minimised the dilution and advection of gametes, presumably enhancing fertilization success (Serrao et al. 1996, Speransky et al. 2000).

I expected that the longer eggs were exposed to waves carrying sperm from neighbouring spawners, the greater the rate of fertilization of those eggs would be. I therefore sampled eggs from individuals as close to the end of the low tide as possible (i.e. just prior to complete immersion by the incoming tide). Because I could not sample whilst the sea-squirts were totally immersed, my estimates of fertilization success are likely to underestimate the actual fertilization rate as further fertilizations are likely to have occurred. It is unlikely, however, that this underestimation is extreme because of the highly turbulent environment to which submerged Pyura stolonifera are exposed. Whereas gametes were exposed to periodic turbulence (waves) followed by calm at low tide, at high tide turbulence appears to be almost continual and not conducive to high rates of fertilization (Denny \& Shibata 1989).

It appears that the movement of sperm between individuals is highly dependent on occasional wave action. Fertilization success of spawning individuals was related to both the proximity of other spawners and the position of spawners relative to the shoreline. Fertilization success decreased rapidly with distance when the nearest spawner was parallel to the shoreline but decreased more slowly when the nearest spawner was perpendicular to the shoreline, i.e. in line with the path of waves. In contrast, the movement of sperm perpen- 
dicular to the motion of waves appears to be minimal. Many other studies of field fertilization rates have shown a strong effect of water flow on fertilization rates (Levitan 1995, Coma \& Lasker 1997) although wave action is usually considered to negatively affect fertilization success (Denny \& Shibata 1989, but see Williams et al. 1997).

Eggs and sperm remained in a viscous matrix on top of spawning individuals throughout the low tide, further reducing the dilution and advection of gametes away from the reef where spawning occurred. This is important given the asynchrony of spawning between reefs. Thomas (1994) suggested that the low mixing qualities of polychaete sperm prevents dilution and thus enhances fertilization success. Because sperm deteriorate faster when they are kept at low concentrations, the retention of sperm within the viscous matrix may act to prolong the viability of spawned sperm (Levitan 1995). Meidel \& Yund (2001) found that seaurchin eggs can remain viable for long periods of time and noted that eggs often remained on the test of spawning individuals. They suggest that, because of these characteristics, the fertilization ecology of broadcast spawning individuals may be similar to that of colonial, brooding invertebrates (Meidel \& Yund 2001). Colonial, brooding invertebrates, such as colonial ascidians, avoid sperm limitation and achieve relatively high fertilization rates by storing and accumulating sperm from the surrounding water (Bishop 1998). In some ways, Meidel \& Yund's (2001) suggestion could be applied here. The eggs that were retained on the top of individual Pyura stolonifera could act as a 'sperm filter', accumulating sperm (and fertilizations) over the low tide. However, since the eggs remained on the tunic for only the length of a single low tide, this period of accumulation appears to be much briefer than for colonial brooders. Therefore, the fertilization ecology of $P$. stolonifera may represent an intermediate between the traditional view of broadcast spawners and the emerging view of brooding colonial invertebrates.

Despite the benefits outlined above, spawning gametes in a viscous matrix, at low tide, may also have some negative consequences for fertilization. In many free-spawning organisms, the presence of sperm in seawater induces spawning in surrounding, reproductively mature, organisms (Pennington 1985, O'Connor \& Heasman 1995). This may be a way of 'fine-tuning' spawning synchrony within populations. In Pyura stolonifera, the movement of sperm appears to be highly limited during low tide. This may explain the observed low spawning synchrony. It may be impossible to achieve high rates of spawning synchrony when sperm is unable to freely disperse throughout a spawning population.

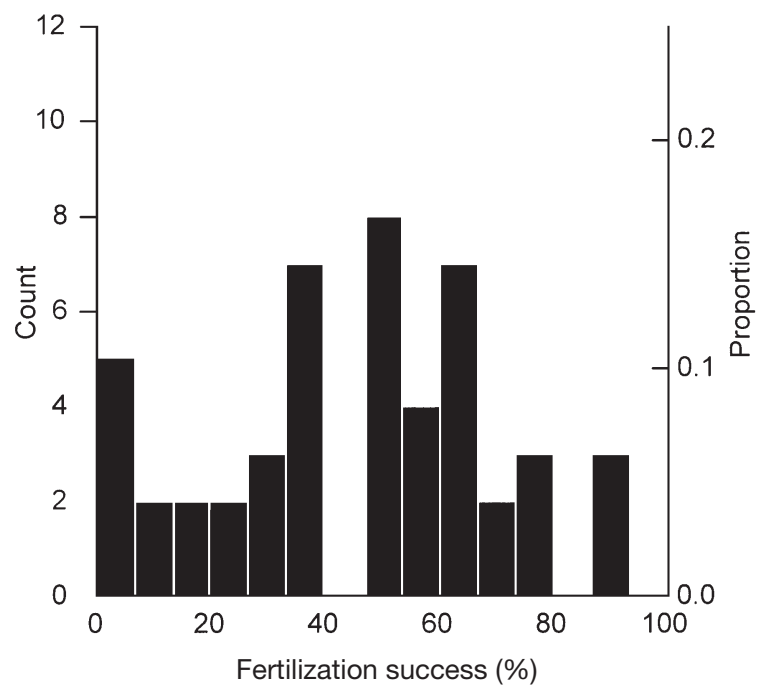

Fig. 3. Pyura stolonifera. Variation in fertilization success from natural spawning during 3 low tides $(n=48)$

Freely spawned gametes typically disperse through the water column, so that it is usually difficult to estimate the reproductive success of any single individual. Therefore, estimates of variation in the reproductive success of an individual within natural, free-spawning populations are scarce. For Pyura stolonifera, fertilization success varied widely amongst individuals (Fig. 3). It is apparent that some individuals contributed disproportionately to the pool of zygotes in the next generation.

During this study, many individuals suffered low rates of fertilization success, but there were 2 very different circumstances that led to such low fertilization success. In individuals that were relatively isolated (nearest spawner $>2 \mathrm{~m}$ ), fertilization success was limited by a low availability of sperm. This was evident by a substantial increase in fertilization success following the experimental addition of sperm. In individuals that were adjacent to other spawners, fertilization success was generally high but not consistently so. In those individuals where fertilization success was approximately $50 \%$ (despite the high local concentration of sperm) the addition of extra sperm did not increase fertilization success. This suggests either that eggs of these individuals were polyspermic, or that some of the eggs were unviable. Sperm concentrations surrounding individuals that were directly adjacent to each other were typically very high and far exceeded those concentrations that are thought to cause high levels of polyspermy in Pyura stolonifera (pers. obs., Marshall et al. 2000). Therefore, in a single spawning event, I found that the reproductive success of some individuals was limited by the scarcity of sperm whilst the 
reproductive success of others was probably reduced by the presence of excess sperm.

This study highlights the importance of observing natural spawning events, as free-spawners may have novel strategies or behaviours that increase fertilization success that cannot be inferred from laboratorybased or manipulative studies.

Acknowledgements. I would like to thank B. Patullo and the many undergraduate students of Melbourne University who assisted me in the field. Special thanks to M. Keough, J. Havenhand and C. Styan for many discussions during and after the observations of Pyura spawning. Thanks also to those who provided helpful improvements for earlier versions of this manuscript, in particular, M. Keough, C. Styan, L. Morris, J. Pechenik, E. Johnston and 2 anonymous reviewers. This study was supported by a Melbourne Research Scholarship.

\section{LITERATURE CITED}

Bishop JDD (1998) Fertilization in the sea: are the hazards of broadcast spawning avoided when free-spawned sperm fertilize retained egg? Proc R Soc Lond B 265:725-731

Brawley SH (1992) Fertilisation in natural populations of the dioecious brown alga Fucus ceranoides and the importance of the polyspermy block. Mar Biol 113:145-157

Brawley SH, Johnson LE, Pearson G, Speransky V, Li R, Serrao EA (1999) Gamete release at low tide in fucoid algae: maladaptive or advantageous? Am Zool 39:218-231

Clareboudt M (1999) Fertilisation success in spatially distributed populations of benthic free-spawners: a simulation model. Ecol Model 121:221-233

Coma R, Lasker HR (1997) Effects of spatial distribution and reproductive biology on in situ fertilisation rates of a broadcast-spawning invertebrate. Biol Bull 193:20-29

Denny MW, Shibata MF (1989) Consequences of surf-zone turbulence for settlement and external fertilisation. Am Nat 134:859-889

Fuke M, Numakunai T (1996) Establishment of self-sterility of eggs in the ovary of the solitary ascidian, Halocynthia roretzi. Roux's Arch Dev Biol 205:391-400

Lambert CC, Lambert G (1981) Formation of the block to polyspermy in ascidian eggs: time course, ion requirements and the role of the accessory cells. J Exp Zool 217: 291-295

Lasiak T (1990) Asynchronous reproductive activity in the

Editorial responsibility: Roger Hughes (Contributing Editor), Bangor, Wales, UK broadcast spawner Cellana capensis. J Molluscan Stud $56: 69-81$

Levitan DR (1995) The ecology of fertilisation in free-spawning invertebrates. In: McEdward LR (ed) Ecology of marine invertebrate larvae. CRC Press, Boca Raton, FL, p 124-152

Levitan DR, Petersen C (1995) Sperm limitation in the sea. Trends Ecol Evol 10:228-231

Marshall DJ, Styan CA, Keough MJ (2000) Intraspecific covariation between egg and body size affects fertilisation kinetics in free-spawning marine invertebrates. Mar Ecol Prog Ser 195:305-309

Meidel SK, Yund PO (2001) Egg longevity and timeintegrated fertilization in a temperate sea urchin (Strogylocentrotus droebachiensis). Biol Bull 201:84-94

O'Connor WA, Heasman MP (1995) Spawning induction and fertilisation in the doughboy scallop Chlamys (Mimachalmys) asperrima. Aquaculture 136:117-129

Parsons GJ, Robinson SMC, Chandler RA, Davidson LA, Lanteigne M, Dadswell MJ (1992) Intra-annual and longterm patterns in the reproductive cycle of giant scallops Placopecten magellanicus (Bivalvia: Pectinidae) from Passamaquoddy Bay, New Brunswick, Canada. Mar Ecol Prog Ser 80:203-214

Pennington JT (1985) The ecology of fertilisation of echinoid eggs: the consequences of sperm dilution, adult aggregation and synchronous spawning. Biol Bull 169:417-430

Powell DK, Tyler PA, Peck LS (2001) Effect of sperm concentration and sperm ageing on fertilisation success in the Antarctic soft-shelled clam Laternula elliptica and the Antarctic limpet Nacella concinna. Mar Ecol Prog Ser 215: 191-200

Serrao EA, Pearson G, Kautsky L, Brawley SH (1996) Successful external fertilisation in turbulent environments. Proc Natl Acad Sci USA 93:5286-5290

Speransky SR, Brawley SH, Halteman WA (2000) Gamete release is increased by calm conditions in the coenocytic green alga Bryopsis (Chlorophyta). J Phycol 36:730-739

Styan CA, Butler AJ (2000) Fitting fertilisation kinetics models for free-spawning marine invertebrates. Mar Biol 137:943-951

Thomas FIM (1994) Transporting and mixing of gametes in 3 free-spawning polychaete annelids, Phragmatopoma californica (Fewkes), Sabellaria cementarium (Moore), and Schizobranchia insignis (Bush). J Exp Mar Biol Ecol 179: 11-27

Williams ME, Bentley MG, Hardege JD (1997) Assessment of field fertilisation success in the infaunal polychaete Arenicola marina (L.). Invertebr Reprod Dev 31:189-197

Yund PO (2000) How severe is sperm limitation in natural populations of free-spawners? Trends Ecol Evol 15:10-12

Submitted: October 9, 2001; Accepted: February 26, 2002

Proofs received from author(s): May 24, 2002 